\title{
LIQUID CHROMATOGRAPHY-UV DETERMINATION OF HEAVY METAL IONS IN ENVIRONMENTAL SAMPLES USING DISPERSIVE LIQUID-LIQUID MICROEXTRACTION COUPLED WITH MAGNETIC NANOPARTICLES
}

\author{
WU, H. Z. ${ }^{*}-$ MENG, L. F. ${ }^{2}$ \\ ${ }^{1}$ College of Mining Engineering, Guizhou University of Engineering Science \\ Guizhou Province 551700, China \\ ${ }^{2}$ College of Chemical Engineering, Key Laboratory of Medicinal Plants for Bijie City, Guizhou \\ University of Engineering Science, Bijie 551700, China \\ *Corresponding author \\ e-mail: 554214954@qq.com
}

(Received 25 $5^{\text {th }}$ Aug 2018; accepted $6^{\text {th }}$ Nov 2018)

\begin{abstract}
A novel, rapid low-density solvent based dispersive liquid-liquid microextraction combined with magnetic nanoparticles has been developed for extraction and preconcentration of $\mathrm{Cr}^{2+}, \mathrm{Ni}^{+}, \mathrm{Co}^{2+}$, $\mathrm{Hg}^{+}$in environmental samples prior to liquid chromatography with $\mathrm{UV}$ analysis. In the proposed method, the Schiff base was used as a complexing agent and the environmental samples were treated with acetonitrile/water $(60: 40, \mathrm{v} / \mathrm{v})$ which was then utilized as disperser solvent in the dispersive liquid-liquid microextraction process along with using 1-octanol as extractant. In magnetic solid phase extraction approach, hydrophobic magnetic nanoparticles were used to retrieve and separate the 1-octanol in the dispersive liquid-liquid microextraction step. In fact the target of magnetic solid phase extraction was the 1-octanol rather than the metal ions directly. Several parameters including the volume of extractant, the $\mathrm{pH}$ of the sample, the concentration of complexing agent, the volume of magnetic nanoparticles were optimized. Under the optimized conditions, there coveries obtained for each metal ion ranged from 86 to $106 \%$ with relative standard deviations lower than $5.6 \%$. The limit of detection were $0.05 \mu \mathrm{g} \mathrm{L}^{-1} \mathrm{for}^{2+}$, $0.05 \mu \mathrm{g} \mathrm{L}-1$ for $\mathrm{Ni}^{+}, 0.06 \mu \mathrm{g} \mathrm{L}^{-1}$ for $\mathrm{Co}^{2+}, 0.05 \mu \mathrm{g} \mathrm{L}-1$ for $\mathrm{Hg}^{+}$, respectively. The preconcentration factors were 205, 200, 195 and 190 for $\mathrm{Cr}^{2+}, \mathrm{Ni}^{+}, \mathrm{Co}^{2+}$ and $\mathrm{Hg}^{+}$, respectively. The presented method has been successfully used for the determination of metal ions in real water samples.
\end{abstract}

Keywords: preconcentration, 1-octanol, DLLME, hydrophobic magnetic nanoparticles, LC-UV

\section{Introduction}

Heavy and transition metal ions are distributed widely in biological systems and the environment, and play important roles in many biological and environmental processes (Trautwein, 1997). Excess amount of these ions is, however, toxic. Lead poisoning can cause a variety of diseases, such as muscle paralysis, memory loss, irritability, and anemia (Strużyńska et al., 1997; Rifai et al., 1993; Rezende et al., 2011). The World Health Organization (WHO) has released the guide-lines for drinking water quality containing the guide line value of $10 \mu \mathrm{g} \mathrm{L}^{-1}$ for lead (WHO, 2006). Cadmium is not regarded as essential to human life and is known to damage organs including the kidneys, liver and lungs (Pourreza et al., 2010; Zhang et al., 2010). Methods for detecting the presence of one or several of these ions are thus urgently needed, and if the detection method could identify different component of the analytes, it would be an excellent improvement compared with other sensing methods. Although many methods for their analysis have been well developed, existing methods require complex equipments and sophisticated operations. 
In many cases the determination of trace metal ions in various samples such as natural and waste water, biological and alloy samples, the direct determination with various instrumental methods is not possible owing to matrix effect and low concentration of metal ions in a sample (Andruch et al., 2012a). Thus separation and preconcentration procedures are required for elimination or minimization of matrix effects and concomitants, lowering the detection limit of many metals with different techniques and enhancing the delectability for many metals. A variety of procedures for preconcentration of metals, such as solid phase extraction (SPE) (Andruch et al., 2012b; Baig et al., 2009), liquid-liquid extraction (LLE) (Duran et al., 2007; Karami et al., 2008; Fritz et al., 2000), coprecipitation, ion-exchange (Kocúrová et al., 2011), flotation (Li et al., 2009), and cloud point extraction (CPE) have been developed (Mohammad et al., 2013; Nascentes et al., 2003; Parham et al., 2009; Rezende et al., 2011; Tuzen et al., 2006). SPE is one of the most frequently employed methods, as it is surface-dependent processes and their efficiency directly depends on the particle size and the surface area of the sorbent (Taylor et al., 1996; Tang et al., 2004). Dispersive liquid-liquid microextraction (DLLME) has been brought up as an exciting microextraction technique in 2006 (Yuet al., 2014; El-Shahawi et al., 2013; Rezaee et al., 2006).

In this procedure, a mixture of high density organic solvent (serving as extraction solvent) and water miscible polar dispersive solvent (dispersive solvent) is rapidly injected into an aqueous sample to form an emulsion consisting of fine droplets of the extraction solvent, dispersive solvent, and water. Due to the extraction solvent being highly dispersed in the aqueous phase, the surface area between extraction solvent and sample solution is infinitely large, thus speeding up the extraction. While, the main disadvantage of DLLME is that the extraction solvent is generally limited to solvents with higher density than water in order to be sedimented by centrifugation, typically chlorinated solvents such as chlorobenzene, chloroform, and tetrachloromethane, all of them are potentially toxic to humans and the environment.

Then, another microextraction technique based on magnetic nanoparticles (MNPs) has gained research interest since the MNPs can be easily isolated from matrix by using an external magnetic field without retaining residual magnetization after its removal (Giannoulis et al., 2013; Shih et al., 2014; Gómez-Pastora et al., 2014; Zou et al., 2013). Also MNPs offer a significantly higher surface area-to-volume ratio and a shorter diffusion route than conventional sorbents, resulting in high extraction capacity, rapid extraction dynamics and high extraction efficiencies (Faraji et al., 2010; Chen et al., 2011; Román et al., 2011).

By combining the merits of the dispersive liquid-liquid microextraction (DLLME) and magnetic solid phase extraction (MSPE) techniques, a new sample preparation method was proposed to trace metal ions of environmental samples. The applications of magnetic nanoparticles in biotechnology and environmental, and so on, has attracted considerable attention in recent years, because of their rapid adsorption ability, surface modification, easy to separation and good biocompatibility etc. The quick separation and excellent adsorption performance of magnetic nanoparticles have gained increasing application in sample pretreatment. The magnetic nanoparticles with suitable surface modification are capable of binding molecules selectively. Magnetic nanoparticles and the magnetic separations, magnetic detections have advantages of rapidity, convenience and high selectivity.

This is the first report regarding preconcentration of $\mathrm{Cr}^{2+}, \mathrm{Ni}^{2+}, \mathrm{Co}^{2+}, \mathrm{Hg}^{+}$by DLLME-MSPE prior to liquid chromatography-UV analysis. A novel, rapid low- 
density solvent based dispersive liquid-liquid microextraction combined with magnetic nanoparticles has been developed for extraction and preconcentration of $\mathrm{Cr}^{2+}, \mathrm{Ni}^{+}, \mathrm{Co}^{2+}$, $\mathrm{Hg}^{+}$in environmental samples prior to liquid chromatography with UV analysis.

\section{Materials and methods}

\section{Chemicals and materials}

The standards of $\mathrm{Cr}^{2+}, \mathrm{Ni}^{+}, \mathrm{Co}^{2+}, \mathrm{Hg}^{+}\left(1000 \mathrm{mg} \mathrm{L}{ }^{-1}\right)$ were purchased from National standard material network (Beijing, China). Working standard solutions were freshly prepared by diluting the stock solutions with high-purity water. 1-hexanol, 1-heptanol, 1-octanol, 1-nonanol, 1-decanol and decanoic acid were obtained from the Aladdin Reagent Corporation (Shanghai, China). As a complexing agent, the Schiff base was from our own laboratory. $\mathrm{FeCl}_{3} \cdot 6 \mathrm{H}_{2} \mathrm{O}, \mathrm{FeCl}_{2} \cdot 4 \mathrm{H}_{2} \mathrm{O}$, ammonium nitrate and the other used chemicals were supplied by Tianjinzhiyuan (Tianjin, China).

\section{Instrumentation}

High-purity deionized and doubly distilled water (UPS-I40L, Ulupure, Shanghai) was used during this study. A pH-meter (PHS-3E, China) was used for $\mathrm{pH}$ measurements. An ultrasonic homogenizer (LTB-300, China) equipped was used as a dispersing agent. A centrifuge (TDZ4-WS, China), with a centrifugation speed in the range from 500 to $6000 \mathrm{rpm}$, was used for phases separation after the microextraction procedure. A High performance liquid chromatography system (Agileng 1260, Agilent, USA), which consisted of an UV detector, was used for the analysis.

\section{Real sample preparation}

Environmental water samples were from local river water and lake water and were analysed by DLLME-MSPE/LC-UV procedure. All water samples were stored at $4{ }^{\circ} \mathrm{C}$.

\section{Synthesis of magnetite nanoparticles (MNPs)}

Preparation of magnetic nano materials $\mathrm{Fe}_{3} \mathrm{O}_{4}$ by hydrothermal reduction method. The $\mathrm{FeCl}_{3}$ was reduced to $\mathrm{Fe}_{3} \mathrm{O}_{4}$ by using ethylene glycol. The addition of anhydrous sodium acetate and surfactant polyethylene glycol was added to prevent the agglomeration of particles. The specific reaction condition, $1.35 \mathrm{gFeCl}_{3} \cdot 6 \mathrm{H}_{2} \mathrm{O}$ dissolved in $40 \mathrm{ml}$ of glycol, adding $3.6 \mathrm{~g}$ anhydrous sodium acetate and $1.0 \mathrm{~g}$ polyethylene glycol under magnetic stirring, at $60^{\circ} \mathrm{C}$ under vigorous stirring until completely dissolved, then the mixed solution into the reaction kettle in a $50 \mathrm{~mL}$, under $200^{\circ} \mathrm{C}$ reacted $12 \mathrm{~h}$ and then cooled to room temperature. The synthesis of $\mathrm{Fe}_{3} \mathrm{O}_{4}$ nano particles with water and ethanol alternate cleaning, vacuum drying at $80^{\circ} \mathrm{C}$.

\section{Extraction procedure}

DLLME step

A $15 \mathrm{~mL}$ aliquot of the sample solution containing $\mathrm{Cr}^{2+}, \mathrm{Ni}^{+}, \mathrm{Co}^{2+}, \mathrm{Hg}^{+}$was transferred into a $50 \mathrm{~mL}$ glass test tube. The $\mathrm{pH}$ of the sample was adjusted to 5.0 with the acetate buffer. Then $500 \mu \mathrm{L} \mathrm{10 \%} \mathrm{w/v} \mathrm{Schiff} \mathrm{base} \mathrm{(complexing} \mathrm{agent)} \mathrm{and} 80 \mu \mathrm{L}$ of 1-octanol (as extraction solvent of DLLME) and the acetonitrile/water (80:20, v/v) 
extract (used as disperser solvent) were added and the mixture was diluted to $40 \mathrm{~mL}$ by deionized water. Then, the tube was sealed and swirled on a vortex agitator at $2000 \mathrm{rpm}$ for $30 \mathrm{~s}$ to accelerate the formation of the fine droplets of the extraction solvent and to enhance the transfer of the analytes.

\section{MSPE step}

$50 \mathrm{mg}$ of the synthetic magnetic nanoparticles were quickly added into the upper tube and the mixture was vigorously blended using a vortex agitator for $60 \mathrm{~s}$ at $5000 \mathrm{rpm}$. The $\mathrm{Cr}^{2+}, \mathrm{Ni}^{+}, \mathrm{Co}^{2+}, \mathrm{Hg}^{+}$(complexes of Schiff base)-containing 1-octanol was successfully partitioned on the surface of MNPs. Subsequently, a magnet was held next to the outer wall of the test tube to attract and isolate the MNPs, and the sample solution was discarded by decanting it. After then, an aliquot of water was added into the vial to rinse the residue. Ultimately, $200 \mu \mathrm{L}$ of methanol was used to desorb the 1octanol as well as the $\mathrm{Cr}^{2+}, \mathrm{Ni}^{+}, \mathrm{Co}^{2+}, \mathrm{Hg}^{+}$from the MNPs by swirling for $30 \mathrm{~s}$ and $10 \mu \mathrm{L}$ of the eluent was used for LC-UV analysis.

\section{Liquid chromatography}

A $10 \mu \mathrm{L}$ aliquot of the extractant phase was injected into the liquid chromatography with UV detector. An Agilent C18-AR column $(250 \times 4.6 \mathrm{~mm}, 5 \mu \mathrm{m}$ particle size $)$ was used as the analytical column. The mobile phase consisted of methanol/water at a ratio of $65 / 35(\mathrm{v} / \mathrm{v})$. The flow rate of the mobile phase was at $1.0 \mathrm{~mL} \mathrm{~min}^{-1}$ and the detection wavelength was set at $256 \mathrm{~nm}$.

\section{Results and discussion}

\section{Characterization of decanoic acid@ $\mathrm{Fe}_{3} \mathrm{O}_{4}$ nanoparticles}

The size and morphological features of decanoic acid@ $\mathrm{Fe}_{3} \mathrm{O}_{4}\left(\mathrm{DA} @ \mathrm{Fe}_{3} \mathrm{O}_{4}\right)$ MNPs were visualized with Transmission electron microscope (TEM). As can be seen in Figure 1, the MNPs have an average size of about $10 \mathrm{~nm}$. The prepared DA@ $@ \mathrm{Fe}_{3} \mathrm{O}_{4}$ NPs were stabilized against agglomeration by a monolayer of decanoic acid. And the edge morphology of DA@ $@ \mathrm{Fe}_{3} \mathrm{O}_{4}$ NPs became blurred because the particles' surface was encapsulated with 10 carbons of acid.

The functional groups of DA-MNPs were identified by Fourier Transform Infrared Spectrometer (FT-IR). The FT-IR spectra of DA-MNPs and 1-octanol-DA-MNPs are shown in Figure 2. The spectrum of DA-NMPs exhibited strong bands at 621 and $3434 \mathrm{~cm}^{-1}$ due to $\mathrm{Fe}-\mathrm{O}-\mathrm{Fe}$ and $\mathrm{O}-\mathrm{H}$ stretching vibrations of magnetic nanoparticles. The peaks at 2924 and $2849 \mathrm{~cm}^{-1}$ were attributed to the $\mathrm{C}-\mathrm{H}$ stretching vibrations of decanoic acid and the peak at $1599 \mathrm{~cm}^{-1}$ contributed to the $\mathrm{C}=\mathrm{O}$ stretch band of the carboxyl group. All these adsorption peaks confirmed the successful coating of $\mathrm{Fe}_{3} \mathrm{O}_{4}$ nanoparticles by DA. 


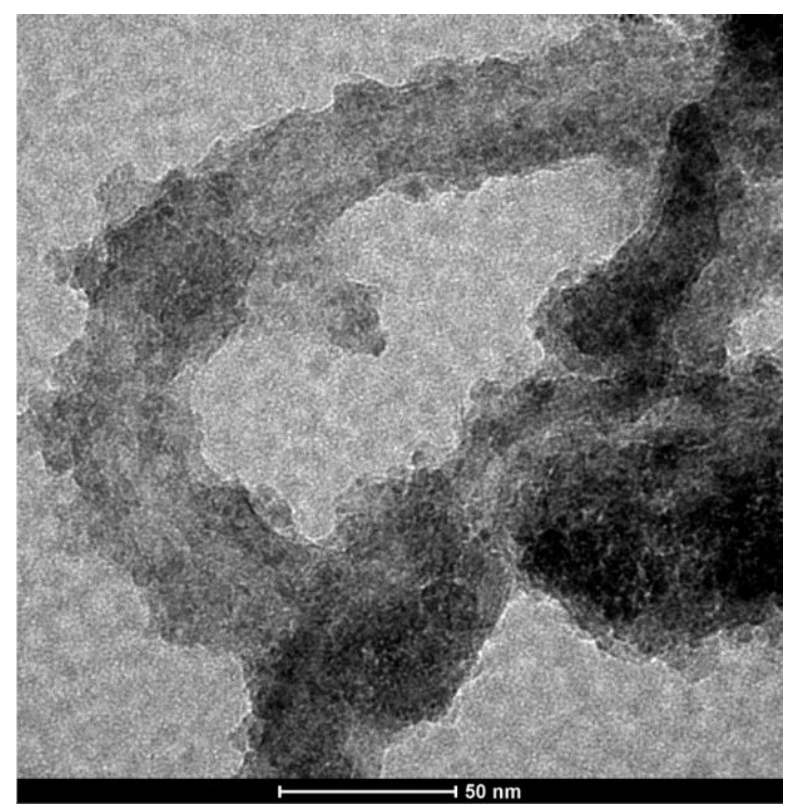

Figure 1. Transmission electron microscope images of synthesized $\mathrm{Fe}_{3} \mathrm{O}_{4} @ M N P s$

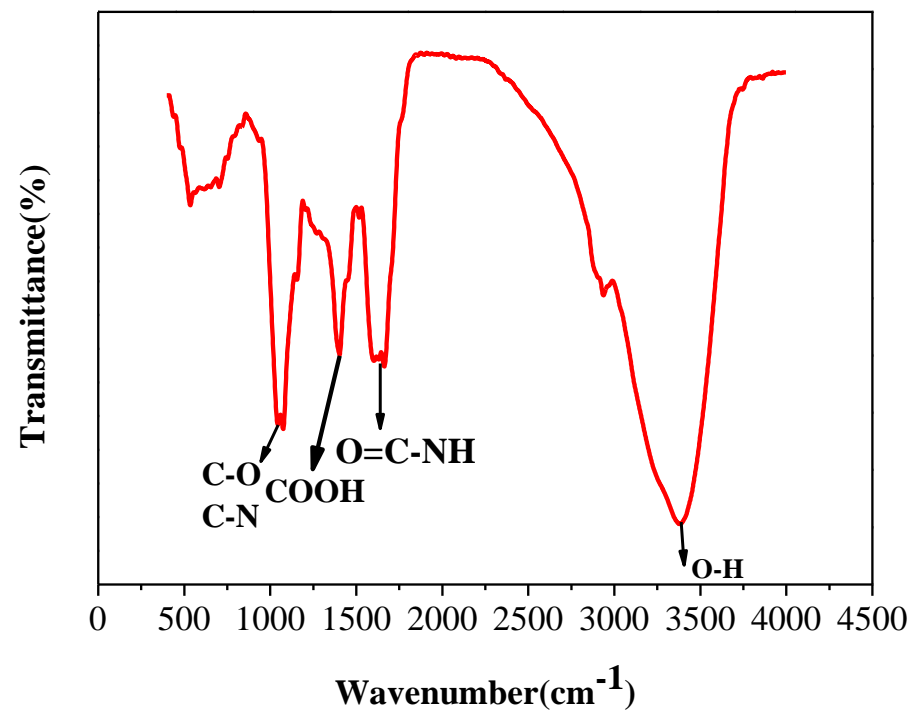

Figure 2. Fourier transform infrared spectras of $\mathrm{Fe}_{3} \mathrm{O}_{4}$ magnetic nanoparticles

\section{Optimization of the DLLME-MSPE method}

During the two-step extraction procedure, several parameters affect the extraction performance and the recoveries. Several parameters, including sample $\mathrm{pH}$, the concentration of complexing agent, the type and volume of extraction solvent, equilibration time, amount of MNPs were optimized by investigation a single parameter when the other parameters remained unchanged.

\section{Selection of the disperser solvent}

The applicability of several organic solvents including $\mathrm{MeOH}, \mathrm{MeCN}, \mathrm{EtOH}, \mathrm{MeOH}$ $80 \%$ and $\mathrm{MeCN} 80 \%$ was investigated in the preliminary experiments taking into 
account that it should used to primary extract of the analytes from real water samples must then act as disperser solvent in DLLME process. Figure 3 shows the recoveries of the whole procedure (extraction + DLLME + MSPE) of all extraction solvents tested. The results revealed that the maximum extraction efficiency was achieved by $\mathrm{MeCN} /$ water $(80: 20 \mathrm{v} / \mathrm{v})$.

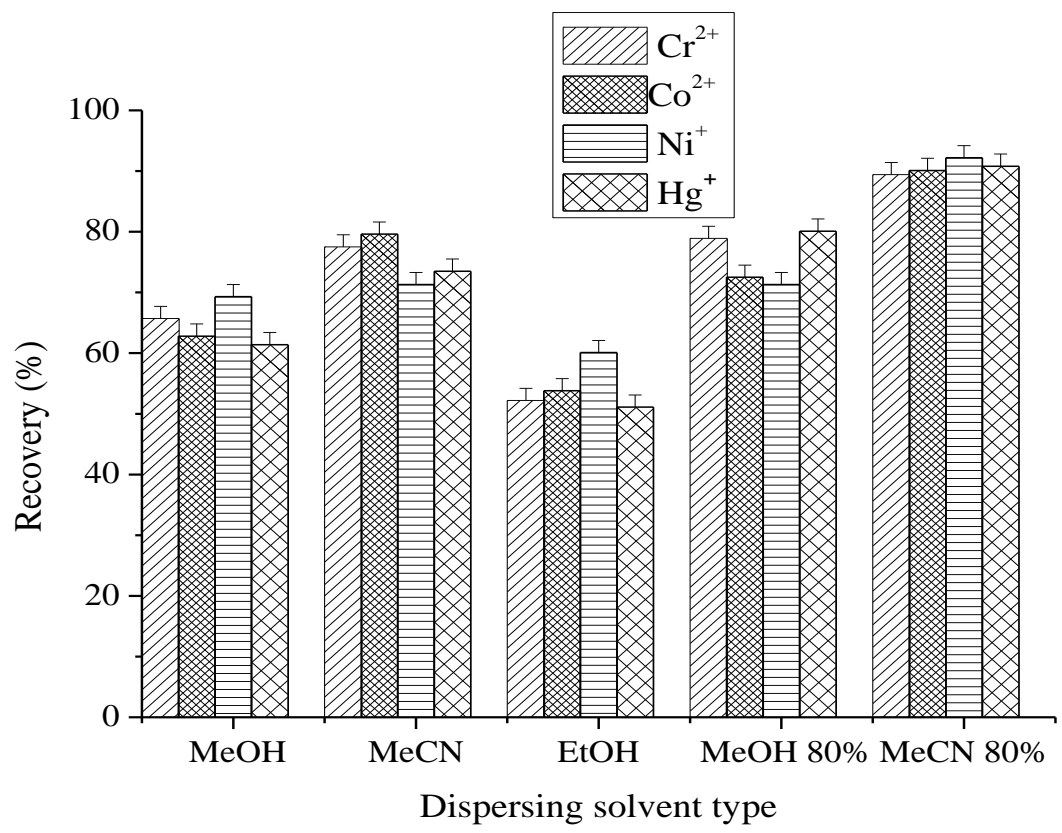

Figure 3. Effect of dispersing solvent

To study the volume effect of disperser solvent, it was varied from 4 to12 $\mathrm{mL}$ in the interval of $2 \mathrm{~mL}$ while extraction solvent was kept at $80 \mu \mathrm{L}$. The obtained results showed that the extraction efficiency increased with increasing the volume of $\mathrm{MeCN}$ $80 \%$ up to $10 \mathrm{~mL}$ and then dropped down slightly above $10 \mathrm{~mL}$ due to decreasing the distribution ratio.

Therefore $10 \mathrm{~mL} \mathrm{MeCN} 80 \%$ was selected as both the extraction solvent of $\mathrm{Cr}^{2+}$, $\mathrm{Ni}^{+}, \mathrm{Co}^{2+}, \mathrm{Hg}^{+}$from water samples and as disperser solvent in DLLME for subsequent experiments.

\section{Effect of solution $\mathrm{pH}$}

The effect of sample $\mathrm{pH}$ was investigated in the range of 2.0-9.0. Adjustment was done using hydrochloric acid, sodium hydroxide and acetate buffer. The achieved areas of the liquid chromatographic peaks were the highest at $\mathrm{pH}=5.0$ and these conditions were used for further experiments.

\section{Selection of extraction solvent}

Selection of appropriate extraction solvent is of great importance in microextraction technique in order to obtain efficient extraction. For the DLLME, the extraction solvent should meet the following requirements: (1) be immiscible with aqueous solution (2) able to extract the analytes, and (3) possess low toxicity. To avoid the use of more highly toxic solvents such as trichloromethane, tetrachloromethane, tetrachloroethylene, 
chlorobenzene etc., five low density organic alcohol including 1-hexanol (density, $\left.\mathrm{d}=0.819 \mathrm{~g} \mathrm{~mL}^{-1}\right), 1$-heptanol $\left(\mathrm{d}=0.820 \mathrm{~g} \mathrm{~mL}^{-1}\right), 1$-octanol $\left(\mathrm{d}=0.821 \mathrm{~g} \mathrm{~mL}^{-1}\right), 1$ nonanol $\left(\mathrm{d}=0.827 \mathrm{~g} \mathrm{~mL}^{-1}\right)$, and 1-decanol $\left(\mathrm{d}=0.828 \mathrm{~g} \mathrm{~mL}^{-1}\right)$ were evaluated as extractants. Among them a stable cloudy solution and good extraction recovery were observed with 1-octanol. The fine droplets of 1-octanol afford larger surface area to contact with the water sample and can be completely absorbed by MNPs after magnetic separation, so that higher extraction performance can be attained. As can be seen in Figure 4, 1-octanol has higher extraction recovery than those obtained by other extraction solvents for the $\mathrm{Cr}^{2+}, \mathrm{Ni}^{+}, \mathrm{Co}^{2+}, \mathrm{Hg}^{+}$. The volume of $80 \mu \mathrm{L}$ of 1-octanol was selected as an optimum solvent volume for further studies.

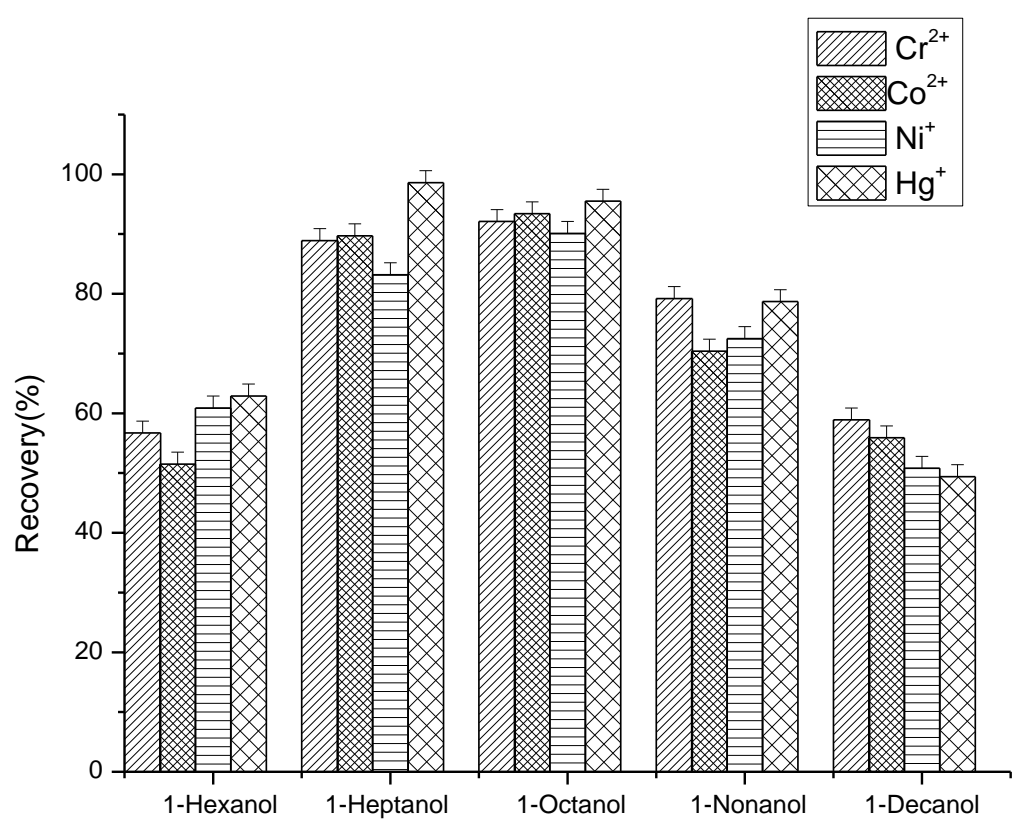

Figure 4. Selection of extraction solvent

\section{Influence of sonication time}

In DLLME extraction, sonication time is defined as an interval time from the occurrence of cloudy solution and before addition of magnetic adsorbents. The effect of extraction time on the adsorption was investigated for 0-120 s. The result showed that sonication time has no influence on extraction efficiency. It is well-known that vortex process is an effective way to enhance mass transfer from aqueous phase to the extraction phase. Consequently, short time was required for extraction. Generally, $30 \mathrm{~s}$ of extraction time was enough to achieve high extraction recovery, and prolonged extraction time did not contribute significantly to an increase in extraction recovery. Therefore, vortex time of $30 \mathrm{~s}$ was selected.

\section{Influence of concentration of Schiff base}

Schiff base has the ability to form metal-ligand complexes (1:2) with divalent metal ions. The effect of Schiff base concentration on the formation of metal complexes was studied in the range from 0.05 to $0.50(\%, \mathrm{w} / \mathrm{v})$. The results show that the extraction 
efficiency of metal ions enhances up to $0.20(\%, w / v)$. Hence, $0.30(\%$, w/v) of Schiff base was selected for preconcentration of the metal ions for further experiments.

\section{Influence of amount of MNPs}

After the DLLME procedure, the magnetic sorbents were dispersed in sample solution to rebind 1-octanol. In order to guarantees the quantitative separation of metalscontaining1-octanol from DLLME step, the effect of the amount of DA@ $@ \mathrm{Fe}_{3} \mathrm{O}_{4} \mathrm{MNPs}$ in the solution was investigated in the range from 20 to $80 \mathrm{mg}$. As shown in Figure 5, the extraction recovery for the analytes increased rapidly when the DA@ $@ \mathrm{Fe}_{3} \mathrm{O}_{4} \mathrm{MNPs}$ amount was increased from 20 to $60 \mathrm{mg}$ and then remained almost constant when the amount of the adsorbent was above $60 \mathrm{mg}$. High surface to volume ratio of nanoparticles causes the quantitative extraction could perform using very low amount of adsorbent. Based on the above results, the addition of $60 \mathrm{mg} \mathrm{DA} @ \mathrm{Fe}_{3} \mathrm{O}_{4} \mathrm{MNPs}$ to samples was optimal for magnetic retrieval.

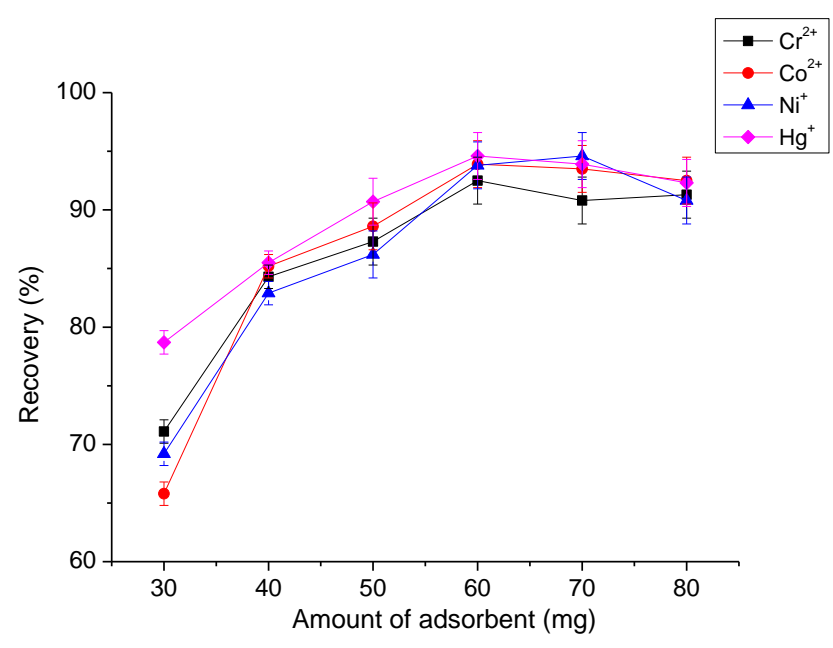

Figure 5. Effect of amount of magnetic nanoparticles

\section{Analytical figures of merit of the DLLME-MSPE method}

The linearity ranges, correlation coefficients, limits of detection and enrichment factors of the $\mathrm{Cr}^{2+}, \mathrm{Ni}^{+}, \mathrm{Co}^{2+}, \mathrm{Hg}^{+}$were evaluated under the optimized DLLME-MSPELC/UV conditions. As listed in Table 1 , the linearity of the method was examined using a mixed working solution of $\mathrm{Cr}^{2+}, \mathrm{Ni}^{+}, \mathrm{Co}^{2+}, \mathrm{Hg}^{+}$with a concentration range of $0.2-$ $100 \mu \mathrm{g} \mathrm{L}^{-1}$ in environmental water sample solutions. All of the analytes exhibited good linearity, with coefficients that ranged from 0.9985 to 0.9990 . The limit of detection (LOD) was calculated on the basis of signal to noise $(\mathrm{S} / \mathrm{N})$ ratio. The $\mathrm{S} / \mathrm{N}=5$ was used for calculation of LOD. The LODs were $0.05 \mu \mathrm{g} \mathrm{\textrm {L } ^ { - 1 }}$ for $\mathrm{Cr}^{2+}, 0.05 \mu \mathrm{g} \mathrm{L}^{-1}$ for $\mathrm{Ni}^{+}$, $0.06 \mu \mathrm{g} \mathrm{L}^{-1}$ for $\mathrm{Co}^{2+}, 0.05 \mu \mathrm{g} \mathrm{L}^{-1}$ for $\mathrm{Hg}^{+}$, respectively. The relative standard deviation (RSD) for five replicate measurements of $1.0 \mu \mathrm{g} \mathrm{L}^{-1}$ in standard solution was $5 \%$. Preconcentration factors calculated as the ratio of the calibration curves slopes for

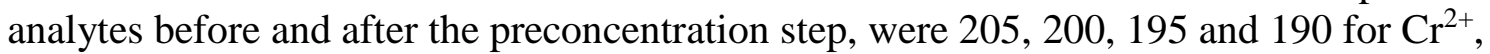
$\mathrm{Ni}^{+}, \mathrm{Co}^{2+}$ and $\mathrm{Hg}^{+}$, respectively. The precision study was carried out in five parallel experiments and provided relative standard deviations below $5.6 \%$. 
Table 1. Figures of merit for the dispersive liquid-liquid microextraction coupled with magnetic solid phase extraction of $\mathrm{Cr}^{2+}, \mathrm{Ni}^{+}, \mathrm{Co}^{2+}, \mathrm{Hg}^{+}(n=5)$

\begin{tabular}{c|c|c|c|c|c|c}
\hline Metal ions & $\begin{array}{c}\mathbf{L R} / \\
\left(\boldsymbol{\mu g} \mathbf{L}^{-1}\right)\end{array}$ & $\mathbf{R}$ & $\begin{array}{c}\mathbf{L O D} / \\
\left(\boldsymbol{\mu g} \mathbf{L}^{-\mathbf{1}}\right)\end{array}$ & $\mathbf{E F}$ & $\mathbf{R S D} / \boldsymbol{\%}$ & Recovery/\% \\
\hline $\mathrm{Cr}^{2+}$ & $0.2-100$ & 0.9989 & 0.05 & 205 & 2.7 & 90 \\
$\mathrm{Co}^{2+}$ & $0.2-100$ & 0.9985 & 0.06 & 195 & 2.8 & 102 \\
$\mathrm{Ni}^{+}$ & $0.2-100$ & 0.9987 & 0.05 & 200 & 3.9 & 95 \\
$\mathrm{Hg}^{+}$ & $0.2-100$ & 0.9990 & 0.05 & 190 & 4.2 & 99 \\
\hline
\end{tabular}

\section{Real sample analysis}

To test the applicability of the proposed method, it was applied to the determination of $\mathrm{Cr}^{2+}, \mathrm{Ni}^{+}, \mathrm{Co}^{2+}$ and $\mathrm{Hg}^{+}$in river and lake water samples. The river water samples were obtained from Liucangqiao River (Bijie, China), the lake water samples from the Jinhai lake wetland park (Bijie, China). Under the recommended experimental conditions, the developed method is employed to determine $\mathrm{Cr}^{2+}, \mathrm{Ni}^{+}, \mathrm{Co}^{2+}$ and $\mathrm{Hg}^{+}$in water samples. And all the water samples are spiked with $\mathrm{Cr}^{2+}, \mathrm{Ni}^{+}, \mathrm{Co}^{2+}$ and $\mathrm{Hg}^{+}$ standard solutions at different concentration levels to assess the matrix effects. Nonspiked samples are also analyzed. The results are shown in Table 2. It shows the developed method applied to the determination of $\mathrm{Cr}^{2+}, \mathrm{Ni}^{+}, \mathrm{Co}^{2+}$ and $\mathrm{Hg}^{+}$in water samples. Also, Figure $6 A$ shows the typical chromatogram of $\mathrm{Cr}^{2+}, \mathrm{Ni}^{+}, \mathrm{Co}^{2+}$ and $\mathrm{Hg}^{+}$at $100 \mu \mathrm{g} \mathrm{L}^{-1}$ without preconcentration, and Figure $6 B$ shows the chromatogram from water sample solution spiked at $100 \mu \mathrm{g} \mathrm{L}^{-1}$ of $\mathrm{Cr}^{2+}, \mathrm{Ni}^{+}, \mathrm{Co}^{2+}$ and $\mathrm{Hg}^{+}$after DLLMEMSPE. Comparison of the chromatograms and acceptable recoveries demonstrated that the interferences from the substances in the real sample had no effects on the performance of the presented method and this method had higher sensitivity for determination of $\mathrm{Cr}^{2+}, \mathrm{Ni}^{+}, \mathrm{Co}^{2+}$ and $\mathrm{Hg}^{+}$.

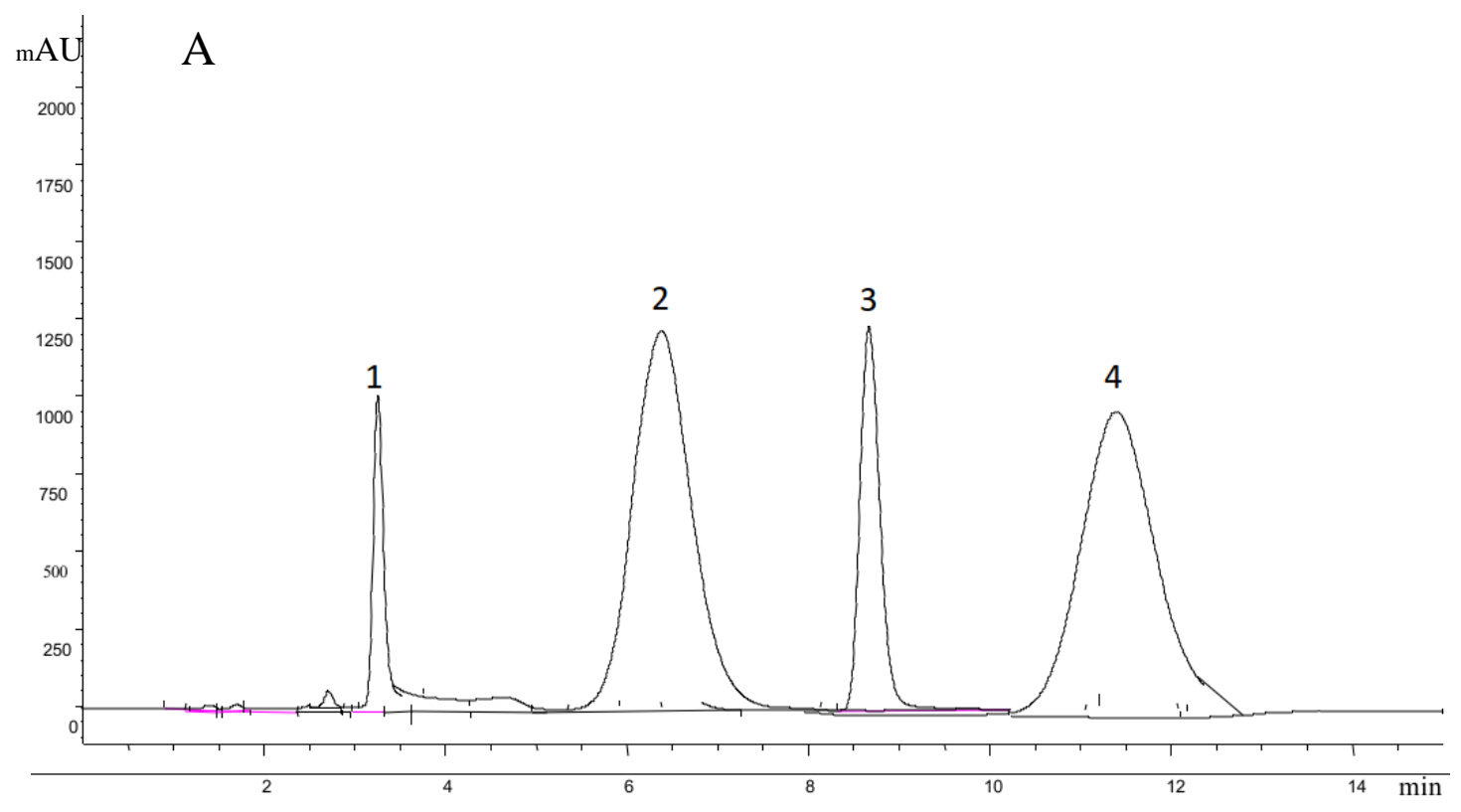




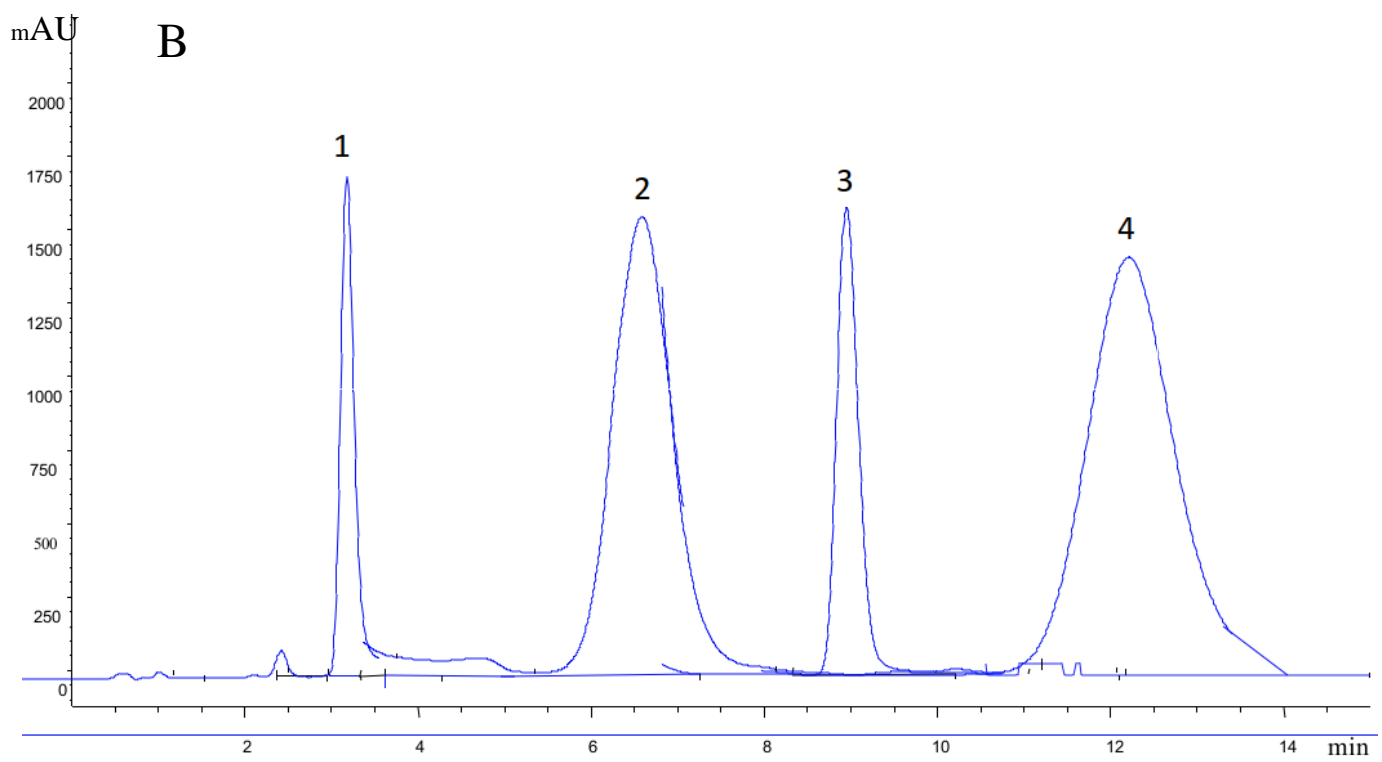

Figure 6. Typical chromatograms: (A) water sample spiked with $\mathrm{Cr}^{2+}, \mathrm{Ni}^{+}, \mathrm{Co}^{2+}$ and $\mathrm{Hg}^{+}$ without dispersive liquid-liquid microextraction-magnetic solid phase extraction and $(B)$ after dispersive liquid-liquid microextraction-magnetic solid phase extraction. $1, \mathrm{Cr}^{2+} ; 2, \mathrm{Ni}^{+} ; 3$, $\mathrm{Co}^{2+} ; 4, \mathrm{Hg}^{+}$

Table 2. Determination of $\mathrm{Cr}^{2+}, \mathrm{Ni}^{+}, \mathrm{Co}^{2+}$ and $\mathrm{Hg}^{+}$and recoveries for water samples

\begin{tabular}{|c|c|c|c|c|}
\hline Water sample & Element & Added $\left(\mu \mathrm{g} \mathrm{L}^{-1}\right)$ & Found $\left(\mu \mathrm{g} \mathrm{L^{-1 } )}\right.$ & $\begin{array}{c}\text { Recovery (\%) } \\
(\mathrm{n}=5)\end{array}$ \\
\hline \multirow[t]{12}{*}{ Lake water } & \multirow{3}{*}{$\mathrm{Cr}^{2+}$} & 0 & $1.12 \pm 0.07$ & \\
\hline & & 5 & $4.98 \pm 0.12$ & 99 \\
\hline & & 10 & $10.26 \pm 0.09$ & 102 \\
\hline & \multirow{3}{*}{$\mathrm{Co}^{2+}$} & 0 & $0.33 \pm 0.11$ & \\
\hline & & 5 & $5.31 \pm 0.05$ & 106 \\
\hline & & 10 & $10.07 \pm 0.03$ & 100 \\
\hline & \multirow{3}{*}{$\mathrm{Ni}^{+}$} & 0 & $0.72 \pm 0.06$ & \\
\hline & & 5 & $5.22 \pm 0.15$ & 90 \\
\hline & & 10 & $10.52 \pm 0.04$ & 98 \\
\hline & \multirow{3}{*}{$\mathrm{Hg}^{+}$} & 0 & $5.71 \pm 0.56$ & \\
\hline & & 5 & $10.95 \pm 0.07$ & 104 \\
\hline & & 10 & $14.32 \pm 0.15$ & 86 \\
\hline \multirow{12}{*}{ River water } & \multirow{3}{*}{$\mathrm{Cr}^{2+}$} & 0 & $0.57 \pm 0.02$ & \\
\hline & & 10 & $10.79 \pm 0.05$ & 102 \\
\hline & & 20 & $19.89 \pm 0.04$ & 96 \\
\hline & \multirow{3}{*}{$\mathrm{Co}^{2+}$} & 0 & $0.37 \pm 0.09$ & \\
\hline & & 10 & $9.98 \pm 0.05$ & 96 \\
\hline & & 20 & $18.08 \pm 0.04$ & 89 \\
\hline & \multirow{3}{*}{$\mathrm{Ni}^{+}$} & 0 & $1.58 \pm 0.03$ & \\
\hline & & 10 & $11.02 \pm 0.07$ & 94 \\
\hline & & 20 & $22.58 \pm 0.09$ & 105 \\
\hline & \multirow{3}{*}{$\mathrm{Hg}^{+}$} & 0 & $1.74 \pm 0.05$ & \\
\hline & & 10 & $11.50 \pm 0.02$ & 98 \\
\hline & & 20 & $19.85 \pm 0.05$ & 90 \\
\hline
\end{tabular}




\section{Comparison with other methods reported}

Comparisons of the mentioned method with other methods reported for extraction and determination of target metal $\mathrm{Cr}, \mathrm{Ni}, \mathrm{Co}$ and $\mathrm{Hg}$ ions were summarized in Table 3 in details. According to the comparison results obtained, the proposed method showed the recovery comparable with most of the previously reported methods, whereas the detection limit (LOD) for the proposed method were obviously lower than those of the reported methods. Moreover, the extraction time was also shorter than for the other methods. It demonstrated that the developed technique was a powerful alternative for rapidly analyzing target metal $\mathrm{Cr}, \mathrm{Ni}, \mathrm{Co}$ and $\mathrm{Hg}$ ions in water samples.

Table 3. Comparisons of analytical methods for the analysis of $\mathrm{Cr}^{2+}, \mathrm{Ni}^{+}, \mathrm{Co}^{2+}$ and $\mathrm{Hg}^{+}$

\begin{tabular}{c|c|c|c|c|c}
\hline Method & LODs ( $\boldsymbol{\mu g} / \mathbf{L})$ & $\begin{array}{c}\text { Extraction } \\
\text { time (min) }\end{array}$ & $\begin{array}{c}\text { Recovery } \\
(\boldsymbol{\%})\end{array}$ & RSD $(\%)$ & Reference \\
\hline SPE-FAAS $^{1}$ & 24.9 & - & $>95 \%$ & $<9.0$ & Pytlakowska (2016) \\
CPE-FAAS $^{2}$ & 1.0 & 30 & $98-105$ & 0.5 & Magda et al. (2016) \\
MSPE-FAAS $^{3}$ & 0.37 & 6 & $96.8-102.5$ & 2.1 & Tahmasebi et al. (2014) \\
DLLME-FAAS $^{4}$ & 90 & $>5$ & $107.5-125.2$ & 0.7 & Özzeybek et al. (2017) \\
DLLME-MSPE-LC/UV $^{5}$ & 0.05 & 5 & $90-102$ & 2.7 & This work \\
\hline
\end{tabular}

${ }^{1}$ SPE-FAAS: solid phase extraction- flame atomic absorption spectrometry

${ }^{2}$ CPE-FAAS: cloud point extraction- flame atomic absorption spectrometry

${ }^{3}$ MSPE-FAAS: magnetic solid phase extraction- flame atomic absorption spectrometry

${ }^{4}$ DLLME-FAAS: dispersive liquid-liquid microextraction- flame atomic absorption spectrometry

${ }^{5}$ DLLME-MSPE-LC/UV: dispersive liquid-liquid microextraction-magnetic solid phase extractionliquid chromatography with UV analysis

\section{Conclusion}

In the present study, a new two-step microextraction technique, based on dispersive liquid-liquid microextraction (DLLME) and magnetic solid phase extraction (MSPE), was developed for determining $\mathrm{Cr}^{2+}, \mathrm{Ni}^{+}, \mathrm{Co}^{2+}$ and $\mathrm{Hg}^{+}$in water samples. A low density solvent (1-octanol) was successfully used in conjunction with magnetic nanoparticles (MNPs) that allowed convenient operation of the procedure. The extraction could be achieved within $2 \mathrm{~min}$ and good extraction efficiencies were obtained. Such facile separation is essential to improve the operation efficiency which avoiding timeconsuming centrifugation or freezing or manual collection of extractant. Coupled with LC-UV analysis, the proposed method exhibited good linearity and acceptable repeatability, and the limits of detection were as low as in the nanogram per milliliter range for $\mathrm{Cr}^{2+}, \mathrm{Ni}^{+}, \mathrm{Co}^{2+}$ and $\mathrm{Hg}^{+}$. In general, this methodology can be considered as a promising procedure for environmental samples or other samples.

Acknowledgements. This research was supported by the Youth Science and technology talent development project of Guizhou Province, Bijie City and Guizhou University of Engineering Science (KY[2018]402 and KY[2018]390), Key Disciplines of Guizhou Province(ZDXK[2016]13), Key Laboratory of Medicinal Plants for Bijie City([2017]05), the Engineering Research Center of Guizhou Province(KY[2018]009)supported this work. The authors are grateful for the referee's help on the manuscript. 
Conflict of interests. The authors declared that there is no conflict of interests regarding the publication of this paper.

\section{REFERENCES}

[1] Andruch, V., Acebal, C. C., Škrlíková, J., Sklenářová, H., Solich, P., Balogh, I. S., Billes, F., Kocúrová, L. (2012a): Automated on-line dispersive liquid-liquid microextraction based on a sequential injection system. - Microchem. J. 100: 77-82.

[2] Andruch, V. Kocúrová, L., Balogh, I. S., Škrlíková, J. (2012b): Recent advances in coupling single-drop and dispersive liquid-liquid microextraction with UV-vis spectrophotometry and related detection techniques. - Microchem. J. 102: 11-17.

[3] Baig, J. A., Kazi, T. G., Shah, A. Q., Arain, M. B., Afridi, H. I., Kandhro, G. A., Khan, S. (2009): Optimization of cloud point extraction and solid phase extraction methods for speciation of arsenic in natural water using multivariate technique. - Anal. Chim. Acta. 651: 57-63.

[4] Chen, L., Wang, T., Tong, J. (2011): Application of derivatized magnetic materials to the separation and the preconcentration of pollutants in water samples. - J. Trac-Trend Anal. Chem 30(7): 1095-1108.

[5] Duran, C., Gundogdu, A., Bulut, V. N., Soylak, M., Elci, M., Sentürk, H. B., Tüfekci, M. (2007): Solid-phase extraction of $\mathrm{Mn}(\mathrm{II}), \mathrm{Co}(\mathrm{II}), \mathrm{Ni}(\mathrm{II}), \mathrm{Cu}(\mathrm{II}), \mathrm{Cd}(\mathrm{II})$ and $\mathrm{Pb}$ (II) ions from environmental samples by Flame atomic absorption spectrometry. - J. Hazard. Mater. 146: 347-355.

[6] El-Shahawi, M. S., Al-Saidi, H. M. (2013): Dispersive liquid-liquid microextraction for chemical speciation and determination of ultra-trace concentrations of metal ions. - Trac. Trends Anal. Chem 44: 12-24.

[7] Faraji, M., Yamini, Y., Saleh, A., Rezaee, M., Ghambarian, M., Hassani, R. (2010): A nanoparticle-based solid-phase extraction procedure followed by flow injection inductively coupled plasma-optical emission spectrometry to determine some heavy metal ions in water samples. - Anal. Chim. Acta 659(1-2): 172-177.

[8] Fritz, J. S., Macka, M. (2000): Solid-phase trapping of solutes for further chromatographic or electrophoretic analysis. - J. Chromatogr. A.902: 137-166.

[9] Giannoulis, K. M., Giokas, D. L., Zhu, Q., Tsogas, G. Z., Vlessidis, A. G. (2013): Surfactant-enhanced liquid-liquid microextraction coupled to micro-solid phase extraction onto highly hydrophobic magnetic nanoparticles. - Microchim. Acta 180(910): 775-782.

[10] Gómez-Pastora, J., Bringas, E., Ortiz, I. (2014): Recent progress and future challenges on the use of high performance magnetic nano-adsorbents in environmental applications. Chem. Eng. J. 256(8): 187-204.

[11] Karami, H., Ghaedi, M., Shokrollahi, A., Rajabi, H. R., Soylak, M., Karami, B. (2008): Development of a selective and sensitive flotation method for determination of trace amount of cobalt, nickel, copper and iron in environmental samples. - J. Hazard. Mater. 151: 26-32.

[12] Kocúrová, L., Balogh, I. S., Nagy, L., Billes, F., Simon, A., Andruch, V. (2011): Application of a bisindocarbocyanine reagent for dispersive liquid-liquid microextraction of silver with subsequent spectrophotometric determination. - Microchem. J. 99: 514522.

[13] Li, Z., Chang, X., Zou, X., Zhu, X., Nie, R., Hu, Z., Li, R. (2009): Chemically-modified activated carbon with ethylenediamine for selective solid-phase extraction and preconcentration of metal ions. - Anal. Chim. Acta 632: 272-277.

[14] Magda, A. A., Magdy, B. M. (2016): Application of CPE-FAAS methodology for the analysis of trace heavy metals in real samples using phenanthraquinone monophenyl 
thiosemicarbazone and triton X-114. - Journal of Analytical \& Bioanalytical Techniques 7(4).

[15] Mohammad, R. J., Firouzjah, A., Rahnama, R. (2013): Solvent-assisted dispersive solid phase extraction. - Talanta 116: 454-459.

[16] Nascentes, C. C., Arruda, M. A. Z. (2003): Cloud point formation based on mixed micelles in the presence of electrolytes for cobalt extraction and preconcentration. Talanta 61: 759-768.

[17] Özzeybek, G., Erarpat, S., Chormey, D. S., Fırat, M., Büyükpınar, Ç., Turak, F., Bakırdere, S. (2017): Sensitive determination of copper in water samples using dispersive liquid-liquid microextraction-slotted quartz tube-flame atomic absorption spectrometry. Microchemical Journal 132: 406-410.

[18] Parham, H., Pourreza, N., Rahbar, N. (2009): Solid phase extraction of lead and cadmium using solid sulfur as a new metal extractor prior to determination by flame atomic absorption spectrometry. - J. Hazard. Mater. 163: 588-592.

[19] Pourreza, N., Ghanemi, K. (2010): Solid phase extraction of cadmium on 2mercaptobenzothiazole loaded on sulfur powder in the medium of ionic liquid 1-butyl-3methylimidazolium hexafluorophosphate and cold vapor generation-atomic absorption spectrometric determination. - J. Hazard. Mater. 178: 566-571.

[20] Pytlakowska, K. (2016): Dispersive micro solid-phase extraction of heavy metals as their complexes with 2-(5-bromo-2-pyridylazo)-5-diethylaminophenol using graphene oxide nanoparticles. - Microchim Acta 183(1): 91-99.

[21] Rezaee, M., Assadi, Y., Milani Hosseini, M. R., Aghaee, E., Ahmadi, F., Berijani, S. (2006): Dispersive liquid-liquid microextraction combined with gas chromatographyflame photometric detection: Very simple, rapid and sensitive method for the determination of organophosphorus pesticides in water. - J. Chromatogr. A. 1123(1): 19.

[22] Rezende, H. C., Nascentes, C. C., Coelho, N. M. M. (2011): Cloud point extraction for determination of cadmium in soft drinks by thermospray flame furnace atomic absorption spectrometry. - Microchem. J. 97: 118-121.

[23] Rifai, N., Cohen, G., Wolf, M., Cohen, L., Faser, C., Savory, J., DePalma, L. (1993): Incidence of lead poisoning in young children from inner city, suburban, and rural communities. - Ther Drug Monit 15: 71.

[24] Román, I. P., Chisvert, A., Canals, A. (2011): Dispersive solid-phase extraction based on oleic acid-coated magnetic nanoparticles followed by gas chromatography-mass spectrometry for UV-filter determination in water samples. - J. Chromatogr. A. 1218(18): 2467.

[25] Shih, H. K., Shu, T. Y., Ponnusamy, V. K., Jen, J. F. (2014): A novel fatty-acid-based intube dispersive liquid-liquid microextraction technique for the rapid determination of nonylphenol and 4-tert-octylphenol in aqueous samples using high-performance liquid chromatography-ultraviolet detection. - Anal. Chim. Acta 854: 70-77.

[26] Strużyńska, L., Walski, M., Gadamski, R., Dabrowska-Bouta, B., Rafałowska, U. (1997): Lead-induced abnormalities in blood-brain barrier permeability in experimental chronic toxicity. - Mol Chem Neuropathol 31: 207.

[27] Tahmasebi, E., Yamini, Y. (2014): Polythiophene-coated $\mathrm{Fe}_{3} \mathrm{O}_{4}$ nanoparticles as a selective adsorbent for magnetic solid-phase extraction of silver (I), gold (III), copper (II) and palladium(II). - Microchim Acta 181(5-6): 543-551.

[28] Tang, A. N., Jiang, D. Q., Yan, X. P. (2004): Cloud point extraction preconcentration for capillary electrophoresis of metal ions. - Anal. Chim. Acta. 507: 203-208.

[29] Taylor, D. B., Kingston, H. M., Nogay, D. J., Koller, D., Hutton, R. J. (1996): On-line solid-phase chelation for the determination of eight metals in environmental waters by inductively coupled plasma mass spectrometry. - J. Anal. At. Spectrom. 11: 187-191.

[30] Trautwein, A. X. (ed.) (1997): Bioinorganic Chemistry. - Wiley-VCH, Weinheim. 
[31] Tuzen, M., Melek, E., Soylak, M. (2006): Celtek clay as sorbent for separation preconcentration of metal ions from environmental samples. - J. Hazard. Mater. 136: 597-603.

[32] Yu, C., Zhang, S., Zhang, J., Li, S., Zhou, W., Gao, H., Lu, R. (2014): An in situ ionic liquid dispersive liquid-liquid microextraction method for the detection of pyrethroids by LC-UV in environmental water samples. - J. Brazil. Chem. Soc. 24(6): 1034-1040.

[33] Zhang, Y., Li, B., Chen, X. (2010): Simple and sensitive detection of dopamine in the presence of high concentration of ascorbic acid using gold nanoparticles as colorimetric probes. - Microchim Acta 168: 107.

[34] Zou, Y., Chen, Y., Yan, Z., Chen, C., Wang, J. (2013): Magnetic solid-phase extraction based on tetrabenzyl modified $\mathrm{Fe}_{3} \mathrm{O}_{4}$ nanoparticles for the analysis of trace polycyclic aromatic hydrocarbons in environmental water samples. - Analyst 138(20): 5904-5912. 